

ISSN 2278 - 0211 (Online)

\section{Improving Effective Porosity of Rocks with Matrix Acidizing Stimulation on Sand Stone Formation}

\author{
Herianto \\ Lecturer, Department of Petreoleum Engineering, \\ Universitas of Pembangunan Nasional "Veteran" Yogyakarta, Indonesia
}

\begin{abstract}
:
Over time the productivity of wells that produced the lower, where one of the reasons that is the fomation damage. Formation damage that often occurs in the field can be a $\mathrm{CaCO}$ precipitation, or swelling clays. As in these wells encountered a problem skin and deposition of debris or deposition of $\mathrm{SiO} 2$ around the wellbore due to the formation of the well is sandstone which have an impact on the rate of production decline. The need for acidification and evaluation to obtain optimum production rate, which in designing a matrix acidizing involves choosing the type of acid and additives, as well as the operating parameter limits acidification, then we evaluate the success of increasing oil production, subsequent to matrix acidizing by comparing several parameters. The parameters used to evaluate matrix acidizing which can be seen from the flow rate, productivity index, flow efficiency, skin, and damage ratio. With the increased flow rate of 22 bopd of oil initially which indicated formation damage and blockages in the well, after the acidification be approximately 52 bopd, then productivity index before acidification bfpd 0.169 / $0.539 \mathrm{psi}$ into bfpd / psi, the decline in value of the original skin +22 mendaji +6 , and flow efficiency becomes 0.2550 .080 that initially, it can be said matrix acidizing the well is successful.
\end{abstract}

Keyword: Production increase, matrix acidizing, well stimulation

\section{Introduction}

From the results of well test at the well, indications of formation damage occurred which resulted in reduced production rate. Where the formation damage caused by the deposition of $\mathrm{SiO2}$, or organic sludge resulting in inhibition of fluid flow from the formation toward the wellbore so that in the end will cause a decline in the productivity of the well. One way that can be done to increase the production rate of wells due to this problem is by way of stimulation. One method of stimulation that will be discussed in this paper is a matrix acidizing.

Matrix acidizingis one way of stimulation with the injection of acid fluid into the formation at an injection pressure above and below the formation pressure fracturing pressure of the formation, in order to react acid rock formations spread radially so as to dissolve the particles that clog the pori- pores around the wellbore and finnaly be able to increase the rate of oil production from the well. In addition, when planning stimulation, need to do the selection of acid type and proper fluid sequence based on the type of formation that correspond so that the process can run well stimulation. The conduct of matrix acidizing stimulation is to improve oil recovery by increasing the permeability of the formation of carbonate rocks, so we get the new linear conductive channel as a way for the reservoir fluids to flow to the wellbore. The data required include the well production data and some data supporting the reservoir.

\section{Review Literature}

Stimulation of matrix acidizing, it is Necessary to Consider the design of Appropriate acidic solution, so that no further damage in the reservoir and injected acid is not excessive. Nowadays, it can be Easily done with the help of realtime monitoring of computerized techniques, the which provide stimulation in the evaluation results. From the measured surface pressure and rate of injection, the computer program when acidizing Estimating progress of skin factor. In this way, the response to stimulation of the well will be evaluated. (E. Ponce da Motta et al 1997)

During the study, HO McLeod focuses on improving the selectivity in the selection and evaluation acidizing success. Where success depends on the evaluation matrix acidizing wells either by using pressure and composition analysis of formations. Then the success of acidification depends on the design to cover all the damage the formation, the selection of solvent and acid composition. (HO McLeod, 1989)

In the above study authors added that to analyze the evaluation of the success of matrix acidizing not only on the choice of acid and additives, as well as limit the operating parameters of the acid production rate, IPR curve, and skin factor alone but can also be done by analyzing the Productivity Index (PI), flow Efficiency and Damage ratio. Then with computerized programming method, E. Ponce Da Motta easily estimate the value of the skin after or prior to matrix 
acidizing. Here the author has its own method to determine the value of the skin, using the equation darcy approach, because the new Acid Job done a few months ago that has not done well testing activities,

\section{Basic Theory}

\subsection{Matrix Acidizing}

Matrix acidizing performed by injecting an acid solution and specific additives directly into the pores of the rock formation surrounding the wellbore with the pressure over the injection of formation pressure and under pressure fracturing the formation. Acid will increase the permeability matrix, either by means of raising pores or dissolving the particles that clog the pores. The main objective of matrix acidizing is to mitigate or eliminate formation damage around the wellbore caused by the activities of drilling, cementing, completion (perforation), production, rework (workover), and stimulation.

Matrix acidizingGenerally performed at a sandstone formation (sandstone) which was marred by calcium carbonate, clay / shale, and feldspar, can also be the formation of carbonate rocks (limestone / dolomite). Although different types of acid, the acid will Achieve effective ability radially at a distance of 1-2 feet from the wellbore. If the well is not damaged (damage), matrix acidizing will not be much help in increasing production.

The Assumptions used in the matrix acidizing operation:

- Homogeneous formation

- Uniform pore size.

- The penetration of the acid solution uniformly and radially.

- Uniform reaction speed decreases with decreasing acid concentration.

- Weight limestone dissolved at each increment distance decreases uniformly until all of the acid used.

3.2. Matrix Acidizing at Sandstone rocks

Acidizing process on a sandstone formation (sandstone) in normal circumstances, there are three stages:

\subsubsection{Preflush (The Period Prior to Flow)}

Preflush fluid normally is hydrochloric acid, with concentrations ranging from 5-15\% and contains corrosion inhibitors and other additives are required. Preflush fluid instead of water from the wellbore and connate water from the area around the borehole, thus minimizing direct contact between the ions of sodium, potassium on the formation water with the reaction products fluorosilicate. Acid also reacts with calcite (calcium carbonate) in the formation, thus reducing or eliminating reaction between $\mathrm{HF}$ acid and calcite. Preflush reduce the use of $\mathrm{HF}$ acid are quite expensive and prevents the formation of calcium fluoride, which can be deposited from the rest of the HF-HCl acid mixture.

\subsubsection{HF-HCl Mixture (Flush)}

Once the fluid is injected next preflush $\mathrm{HCl}-\mathrm{HF}$ mixture (typically $3 \% \mathrm{HF}$ and $12 \% \mathrm{HCl}$ ). $\mathrm{HF}$ reacts with the clay, sandstone, drilling mud or cement filtrate to increase of the permeability around the wellbore. $\mathrm{HCl}$ not react and his presence only serves to keep the $\mathrm{pH}$ remains low, Preventing terendapkannya HF reaction yield.

\subsubsection{Afterflush (The Period after The Flow)}

Afterflush is Necessary to isolate the unreacted $\mathrm{HF}$ formation of water that can be used to clean the tubing and restore wetness formation and acid reaction products do not dissolve.

Selection is based on the formation of acid is attached in Appendix Table 1.

\subsection{Matrix Operations Acidizing}

\subsubsection{Pressure Planning Matrix Acidizing}

A matrix acidizing design must be specific, not only the volume and type of fluid is injected, but Also the maximum allowable injection rate and pressure treatment to Prevent fracture formation.

\subsubsection{Determination of Acid Concentrate}

- Calculate the Dissolving Power (mass of dissolved minerals by a number of acid masses)

$$
\beta=\frac{v_{\text {min eral }} \times M W_{\text {min eral }}}{v_{\text {asam }} \times M W_{\text {asam }}}
$$

- Calculating Volume Concentrate

$\mathrm{V} 1 \mathrm{~V} 2 \mathrm{M} 1=\mathrm{M} 2$

- Determining the volume of acid used

The volume of acid treatment (main acid treatment) can be calculated with the following equation: 


$$
V=7,481 \times \phi \times h x \times\left(r p^{2}-r w^{2}\right)
$$

\subsubsection{Determination Rate}

- The gradient determines the fracturing Formation (GRF)

Gradients fracturing rock formations can be determined by the following equation:

$$
\text { Grf }=\alpha+(\text { Gov }-\alpha) \times\left[\frac{\text { Ps }}{\text { Depth }}\right]
$$

- Determining the formation fracturing pressure

$$
\text { Prf }=\text { Grf } \times \text { Depth }
$$

- Determining Maximum Pressure Acid Injection on Surface (Pmax)

The purpose of this injection pressure calculation is to determine the acid injection pressure at the surface in order to avoid fracturing the formation. Persamannya are:

$$
\begin{aligned}
& P_{\text {pump }}=\left(G_{f}-G_{h a}\right) \times \text { Depth } \\
& \qquad \operatorname{Pmax}=\mathrm{Ph}+\mathrm{P}_{\text {pump }}+\mathrm{P}_{\text {loss }}
\end{aligned}
$$

- Determining Maximum Acid Injection rate

$i_{\max }=\frac{4,917 \times 10^{-6} \times k_{a v g} \times h \times((G f \times D)-\operatorname{Pr})}{\mu \times \ln (r e / r w)}$

To avoid the occurrence of cracking in the formation, injection rate should be less than $i_{\max }$, It is suggested, for practical purposes, an injection rate $<10 \%$ of the imax.

\subsubsection{Implementation Procedures Matrix Acidizing}

Before carrying out the acidification, you need to know about the placement of the fluidduring stimulation acidification. Here there are three stages of pumping fluid during acidification, ie preflush, treatment fluid, and the fluid overflush.

\subsubsection{Pre-Flush}

Pre-flush fluid must be pumped in front of an acid solution to avoidthe direct contact of acid with the formation fluids. It is intended to reduce the possibility of formation of sodium and potassium fluosilicate as a reaction between an acid ions that exist. Reviews These deposits are formed when acid fluosilicate and fluoaluminic meet with potassium or sodium contained in the formation water. The types of pre-flush may be selected include hydrochloric acid, diesel, kerosene and ammonium chloride $(\mathrm{NH} 4 \mathrm{Cl})$.

\subsubsection{Flush or Main Fluid Treatment}

At play is a fluid treatment designed to address damagethat exist in the formation. The fluid used in the acidification treatment depends on the type of rock and reservoir fluid to be stimulated.

\subsubsection{Overflush}

Overflush fluid used to drive the treatment fluid in the formation. fluidThis insures that the acid will react in the formation. Fluid commonly used in overflush is $\mathrm{NH} 4 \mathrm{Cl}, \mathrm{HCl}$ diesel and kerosene. Selection of the type of acid to be used should consider the composition of the rock formations in question, the type of formation fluid, and economic factors. It is intended that the acidification can be beneficial as it should and does not cause side effects as a result of the reaction between an acid with minerals making up the rock that will cause formation of a new precipitate after acidification.

\subsubsection{Evaluation Matrix Acidizing}

Evaluation is done by comparing the success of some of the parameters before and after matrix acidizing.

The success of matrix acidizing may be analyzed by:

- Performance Analysis of Fluid Flow in Porous Media

- Productivity index (PI) and Skin factor

- Skin permeability Analysis (KS)

- Flow Efficiency

- Damage ratio

\section{Methodology}

Planning matrix acidizing and evaluation needs to be done to get the optimal production rate, following Several stages of planning and evaluation matrix acidizing: 
4.1. Design Matrix Acidizing

Covering the choice of acid and additives, as well as the operating parameter limits acidification.

4.2. Evaluation of Success

Evaluation is done by comparing the success of some of the parameters before and after matrix acidizing. Reviews These parameters include:

- The rate of production and IPR curve

- Productivity index (PI) and Skin factor

- Flow Efficiency

- Damage ratio

- Apparent wellbore

\section{Case study}

A production well " $\mathrm{X}$ " in the field "Y" on benuang structure matrix acidizing stimulation will be carried out and will be evaluated with a view to resolving the problems of production in order to increase the productivity of the formation. Well perforation interval "X" in the Annex attached Figure 1. Well before the matrix acidizing have oil flow rate of 12 BOPD, Productivity Index (PI) of 0,085 Bbl / d / psi, skin of +45, damage ratio of 8.13, apparent wellbore by8.5 x 10-21ft and efficiency of flow rates of 0.0462 .

\subsection{Evaluation Planning Matrix Acidizing}

- Calculate Dissolving Power (mass of dissolved minerals by a number of acid masses)

$$
\beta=\frac{v_{\text {min eral }} \times M W_{\text {mineral }}}{v_{\text {asam }} \times M W_{\text {asam }}}
$$

To the reaction between $100 \% \mathrm{HCl}$ : $\mathrm{HF}$ with $\mathrm{SiO} 2$

$$
\begin{aligned}
& 4 \mathrm{HF}+\mathrm{SiO} 2=20 \longrightarrow \mathrm{SiF} 4+2 \mathrm{H} 2 \mathrm{O} \mathrm{MW} \mathrm{SiO2}=60.1 \\
& \mathrm{MW} \mathrm{HF}=\frac{(1)(60.1)}{(6)(20)}=0.5 \frac{\mathrm{Lbm} \mathrm{SiO} 2}{\mathrm{Lbm} \mathrm{HF}}
\end{aligned}
$$

Because using $\mathrm{HCl}$ : $\mathrm{HF} 15 \%$, then:

$ß 15=0: 15$ (SS100) $=0.075 \mathrm{lbSiO} 2 / \mathrm{LBMHCl}: \mathrm{HF}$

- Calculate Dissolving Power Volumetric (X)

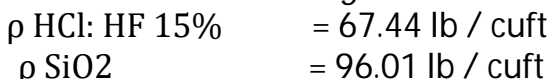

$$
\begin{aligned}
X(15) & =0.075 \times \frac{67.44}{96.01} \\
= & 0052 \frac{f t 3 \text { SiO2 }}{f t 315 \% H C L: H F}
\end{aligned}
$$

- Calculating Volume Concentrate

V1.M1 = V2.M2

338 gall to get $15 \%$ of the concentrate is $32 \% \mathrm{HCL}$ and $40 \% \mathrm{HF}$, at first then in need:

Volume Concentrate HCL $=338 \times 12=$ V2 $\times 32$

$$
\mathrm{V} 2=127 \mathrm{gal}
$$

Thus, the water should be added as much as 211 gal.

Volume Concentrate HF $=338 \times 3=V 2 \times 40$

$$
\mathrm{V} 2 \quad=26 \mathrm{gal}
$$

Thus, the water should be added as much as 312 gal.

Total concentrate volume $=$ Volume HCL $+\mathrm{HF}$

$$
=127 \mathrm{gal}+26 \mathrm{gal}=153 \mathrm{gal}
$$

Water should be added as much as $185 \mathrm{gal}$

- Calculate the gradient of fracturing formations

$$
\begin{aligned}
& G r f=\alpha+\left(G_{o v}-\alpha\right) \frac{P s}{D} \\
& G r f=0.44+(1-0.44) \frac{2708}{7334} \\
& \mathrm{psi} / \mathrm{ft} G r f=0.646
\end{aligned}
$$

- Determination of the formation fracturing pressure

$\operatorname{Pr}=$ GRF $x$ D 
$\operatorname{Pr}=0646 \mathrm{psi} / \mathrm{ft} \times 7334 \mathrm{ft}$

$=4738 \mathrm{psi}$

- Determination of the Maximum Injection Pressure in Surface and Maximum Injection Pressure.

Pinj max $=($ GRF - hydrostatic gradient acid $) \mathrm{x} D$

Pinj $\max =(0646-0.4688) \times 7334$

$$
=1300 \mathrm{psi}
$$

$\mathrm{Sf}=1300-10 \%=1170$ Psi

In the field of applications, the pressure at the surface should not exceed 1170 psi.

$$
\begin{aligned}
\text { Phd } & =\mathrm{Ph}+\mathrm{P}_{\text {pump }}-\mathrm{P}_{\text {loss }} \\
& =(0.052 \times \rho \mathrm{D})+1170-\text { Ploss } \\
& =(0.052 \times(1.0809 \times 8.33) 7334+1170-1024 \\
& =3433+1170-1024 \\
& =3579 \mathrm{Psi}
\end{aligned}
$$

So the maximum injection pressure that must be spent by 3579 Psi.

- Determination of the Maximum Flow Rate

$$
\begin{aligned}
Q_{\text {maks }} & =\frac{4,917 \times 10^{-6} k_{\text {avg }} h\left(P_{r f}-P_{s}\right)}{\mu \ln \left(r_{e} / r_{w}\right)} \\
Q_{\text {maks }} & =1 \mathrm{bpm}
\end{aligned}
$$

In practice the rate of injection that can be used is $90 \%$ of the value of the injection rate in the can at the top, i.e by 0.9 bpm.

- Acid Volume Determination

Vasam $=7.481 \times \pi \times \phi x h x(R p 2-R W 2)$

$$
=7.481 \times 3: 14 \times 0: 15 \times 6.5 \times(3,852-0: 32)
$$

Vasam $=338$ gals

Injection of acid per feet $=338$ gals $/ 9.8 \mathrm{ft}$

$$
=34.5 \mathrm{gal} / \mathrm{ft}
$$

\subsection{Evaluation of Success Matrix Acidizing}

- Calculation Analysis and Preparation Production rate curve IPR

This production rate calculation method Soekarno Pudjo by comparing the rate of production before and after acidizing and manufacturing of IPR curve.

A. Method Sukarno Pudjo

Unknown data before acidification:

- Reservoir pressure (Ps) =2708 psi

- Bottomhole flow pressure (PWF) $=2300 \mathrm{psi}$

- Oil production rate (Qo) $\quad=22$ bopd

- Fluid production rate (Qf) $\quad=69 \quad \mathrm{bfpd}$

- Water cut $\quad=68 \%$

- Bubble point pressure =2531 psi

Unknown data after the acidification:

- Reservoir pressure (Ps) =2708 psi

- Bottomhole flow pressure (PWF) $=2300 \mathrm{psi}$

- Oil production rate $(\mathrm{Q}) \quad=52$ bopd

- Fluid production rate (Qf) $\quad=220 \quad$ bfpd

- Water cut =76 \%

- Bubble point pressure =2531 psi

completion:

- PI before matrix acidizing

$$
\begin{aligned}
& \mathrm{PI}=\frac{\mathrm{q}}{\mathrm{Ps}-\mathrm{pwf}} \\
& \mathrm{PI}=\frac{69}{2708-2300} \\
& \mathrm{PI}=0.169 \mathrm{bfpd} / \mathrm{psi}
\end{aligned}
$$

- PI after matrix acidizing

$$
\begin{aligned}
& P I=\frac{q}{P s-p w f} \\
& P I=\frac{220}{2708-2300}
\end{aligned}
$$


$\mathrm{PI}=0.539 \mathrm{bfpd} / \mathrm{psi}$

Then create graphs plot between Q (bfpd) on the x-axis and y-axis PWF assumptions.

PWF calculation results table vs Qf with Sukarno Pudjo equation before and after matrix acidizing attached in Appendix Tables 2a and 2b. And IPR comparison chart before and after matrix acidizing picture attached in annex 2 .

- Calculation Analysis of PI and Skin Factor

Unknown Data:

- permeability $\quad=85.9 \mathrm{mD}$

- Oil viscosity $(\mu \mathrm{o}) \quad=.207 \quad \mathrm{cp}$

- $\mathrm{Re}$

- $\mathrm{h}$

$=164 \mathrm{ft}$

- Bo

$=6.5 \mathrm{ft}$

- rw

$=1,625 \mathrm{bbl} / \mathrm{stb}$

- ps

$=0,3 \quad \mathrm{ft}$

$=2708 \mathrm{psi}$

- PWF

- Qo before acidification

- Qf before acidification

$=2300 \mathrm{psi}$

$=22$ bopd

$=69 \mathrm{bfpd}$

- Qo after the acidification

$=52 \mathrm{bopd}$

- Qf after the acidification $\quad=220 \mathrm{bfpd}$

completion:

PI ideal $=\frac{0,007082 x k x h}{\mu o x \beta o x \ln \left(\frac{r e}{r w}\right)-0,75+s}$

PI ideal $=\frac{0,007082 \times 85,9 \times 6,5}{0,207 \times 1,625 \times\left(\ln \left(\frac{164}{0,3}\right)-0,75+0\right)}$

$=2: 11 \mathrm{bfpd} / \mathrm{psi}$

Before acidification Matrix

PI test $=$ Qf $/$ (Ps - PWF)

$=69 /(2708-2300)$

$=0.169 \mathrm{bfpd} / \mathrm{psi}$

Before acidification Price Skin Factor Matrix



$0,169=\frac{0,007082 \times 85,9 \times 6,5}{0,207 \times 1,625 \times\left(\ln \left(\frac{164}{0,3}\right)-0,75+s\right)}$

$\mathrm{S}=+22$

After acidification Matrix

PI test $=$ Qf $/$ (Ps - PWF)

$$
=220 /(2708-2300)
$$

$=0539 \mathrm{bfpd} / \mathrm{psi}$

After acidification Price Skin Factor Matrix

$$
\begin{aligned}
\mathrm{PI} & =\frac{0.007082 \times k x h}{\mu o x \beta o x \ln \left(\frac{r e}{r w}\right)-0.75+s} \\
0,539 & =\frac{0,007082 \times 85,9 \times 6,5}{0,207 \times 1,625 \times \ln \left(\frac{164}{0,3}\right)-0,75+s} \\
\mathrm{~S} & =+6
\end{aligned}
$$

On stimulation of matrix acidizing, the value of skin ideal desired by 0 , where the value indicates that there is no formation damage in the formation or the value of skin had been overcome, but the result of the stimulation of matrix acidizing is still worth $(+)$ where at least a little damage to the formation , but it can be said stimulation was successful because of the value of early skin bernial $(+22)$ narrowed to $(+6)$, then the rate of production increased rapidly which can be inferred acid injected material capable of sweeping the rock pores clogged although not dissolve the whole skin in porous rocks. 
- Flow Analysis Calculation of Efficiency (FE)

Unknown Data:

Ideal PI

$$
\begin{aligned}
& =2: 11 \mathrm{bfpd} / \mathrm{psi} \\
& =0.169 \mathrm{bfpd} / \mathrm{psi} \\
& =0.539 \mathrm{bfpd} / \mathrm{psi}
\end{aligned}
$$

PI test (after stimulation)

Calculation:

- Before acidification Matrix

$$
\begin{aligned}
F E & =\frac{\text { PI test }}{\text { PI ideal }} \\
F E & =\frac{0.169}{2.11} \\
F E & =0.080
\end{aligned}
$$

- After acidification Matrix

$$
\begin{aligned}
& F E=\frac{\text { PI test }}{\text { PI ideal }} \\
& F E=\frac{0.539}{2,11} \\
& F E=0.255
\end{aligned}
$$

- Calculation of Apparent wellbore Analysis

(Rw) Apparent =e-s (rw) actual

- apparent wellbore prior to acidizing

(Rw) Apparent $=\mathrm{e} 22 \times 0.3 \mathrm{ft}$

$$
=8: 36 \times 10-11 \mathrm{ft}
$$

- apparent wellbore performed after acidizing

(Rw) Apparent $=\mathrm{e} 6 \times 0.3 \mathrm{ft}$

$$
=7.4 \times 10-4 \mathrm{ft}
$$

\section{Discussion}

Stimulation of acidification on the sandstone generally use a mixture of hydrochloric acid - HF, where the well is used acid 15\% $\mathrm{HCl}+\mathrm{HF}$. Hydrochloric acid alone can sometimes be used in the stimulation of sandstones if there is calcium carbonate ( $\mathrm{CaCO} 3$ ) is high on the sandstone that, but does not affect the mineral silica (SiO2), therefore it is necessary $\mathrm{HF}$ which is used to dissolve the mineral silica ( $\mathrm{SiO} 2$ ) of the , Based on calculations obtained acidification matrix formation fracturing pressure gradient of $0.646 \mathrm{psi} / \mathrm{ft}$ with the same formation fracturing pressure to $4738 \mathrm{psi}$. The maximum injection pressure required to inject the acid so as not to create fissures in the amount of 3921 Psi. The volume of acid used is as much as 338 gallons.

Productivity index calculated based on the result of the penetration of the acid after stimulation resulted in a price of 0.539 bfpd / psi, while the price index of productivity prior to stimulation of $0.0169 \mathrm{bfpd} / \mathrm{psi}$. Based on a comparison of two phase IPR curve obtained after stimulation of the oil flow rate of 52 bopd while before stimulation by 22 bopd, assuming Ps at $2708 \mathrm{psi}$ and $2300 \mathrm{psi}$ of PWF. The success is based on the value of skin one of which can be analyzed from Pressure Buildup Test. In this well PBU Test is only performed prior to acidification, therefore, to know the value of his skin, in this case the author uses Darcy radial flow equation approach in pseudo steady state conditions. Value skin before acidizing worth $(+22)$, while after acidizing value by $(+6)$. In matrix acidizing stimulation, value skin the desired ideal of 0 , where the value indicates that there is no formation damage in the formation or the value of skin had been overcome, but the result of the stimulation of matrix acidizing is still worth ( + ) where at least a little damage to the formation, but it can be said stimulation was successful because of the value of early skin bernial $(+22)$ narrowed to $(+6)$, then the rate of production increased rapidly which can be inferred acid injected material capable of sweeping the rock pores clogged although not dissolve the entire skin on a porous rock.

Besides other parameters commonly used to Evaluate the acidizing job that has been done is an evaluation of the apparent wellbore and flow efficiency. Prior to the acidizing value of its apparent wellbore is8:36 x 10-11ft and after acidizing be $7.4 \times 10-4 \mathrm{ft}$. This may indicate additional wells fingers that are affected by the price berukurangnya skin.

Flow efficiency is defined as the ratio of the productivity index with skin effect with the index of productivity without the influence of the skin. Based on the well flow calculation results Obtained Increased efficiency from 0.080 before acidizing and 0255 after acidizing, this indicates an increase is in the formation to drain the fluid.

With the Increase in oil flow rate, productivity index, the price reduction of skin, and an Increase in the value of the apparent wellbore and flow efficiency, it can be said matrix acidizing wells SUCCESSFUL.

\section{Conclusion}

- Evaluation includes evaluation matrix acidizing design and evaluation of the success that Compares the oil flow rate, productivity index, the price of the skin, damage ratio, wellbore apparent, and flow efficiency before and after matrix acidizing.

- The total volume of acid needed for the wells as much as 338 gallons and price maximum injection pressure is needed is 3.921 psi roomates exceeds the formation pressure of 2708 psi and below the formation fracturing terkanan of 4738 Psi. 
- Wells prior to the acidification of the matrix has the oil flow rate of 22 bopd, Productivity Index (PI) of 0.0169 bfpd / psi, skins at (+22), amounting apparent wellbore 8:36 x 10-11FE ft and prices to be 0.080. Meanwhile, after the acidification matrix oil flow rate to 52 bopd, PI becomes $0.255 \mathrm{bfpd} / \mathrm{psi}$ assuming Ps price of $2708 \mathrm{psi}$ and 2300 psi for PWF, skin becomes (+6), became apparent wellbore7.4 x 10-4ft and FE be 0.187.

- With the increase in oil flow rate, productivity index, the price reduction of skin, and an increase in the value of the apparent wellbore and flow efficiency, it can be said matrix acidizing the well is successful.

\section{References}

i. Al-Dhafeeri A.M., Engler T.W., Nasr-El-Din H.D., "Application of Two Methods to Evaluate Matrix Acidizing Using Real-Time Skin Effect in Saudi Arabia", SPE 73703, USA, 2002.

ii. Allen, TO and Robert, AP, "Operation Production Well Completion, Workover and Stimulation", Third Edition Volume 2, Oil and Gas Consultants International Inc., Tulsa, 1982.Chapter 7: 125-127, 131 to 132.135.

iii. C. Ucendu, L Nwoke, and J. Arukhe., "A New Approach to Matrix Sandstone Acidizing Using a Single-Step HF System: A Case Study Niger Delta", SPE Annual Technical Conference and Exhibition held in San Antonio, Texas, in 2006 ,

iv. Coulter GR, AR Jennings, "A Contemporary Approach to Matrix Acidizing", SPE Prod \& facilities vol. 14, 1999.

v. Economides MJ, Daniel Hill. A., Ehlig Economides. C., "Petroleum Production Systems", Petroleum Engineering Series Prentice Hall, Englewood Cliffs, New Jersey, 1994 Chapter 14: 330, 347-348. Chapter 15: 392, 405.

vi. F. Yang, HA Nasr-El-Din, B. Al-Harbi. "Acidizing Sandstone Reservoirs Using HF and Formic Acid", SPE Internal Sypsosium and Exhibition on Formation Damage Controlheld, Louisiana, in 2012.

vii. McLeod.O.Harry, "Significant Factors for Successful Matrix Acidizing", SPE Journal 20155, USA, 1990.

viii. Da Motta Ponce .e, Dos Santos .MCAJ, Zhu D, and AD Hill, "Field Evaluation and Optimization of Matrix Acidizing Treatments", SPE Journal 37 460, Texas, 1997.

ix. Nicholas Kume, Robert. V. M, and Luckie Erhahon, "New HF Acid System Improves Sandstone Matrix Acidizing Success Ratio By 400\% Over Conventional Mud Acid System in the Niger Delta Basin" SPE Annual Technical Conference and Exhibition held in Houston, Texas, in 1999.

x. R. Taha, Hill. AD, Sepehrnoori. K., "Simulation of Sandstone Matrix Acidizing in Heterogeneous Reservoirs", Journal of Petroleum Energy, Texas, in 1986.

xi. RS Schechter, "Oil Well stimualtion", Englewood Cliffs, 1992. Chapter 16: 482-483, 493.

xii. S. Sherif, Abdelmoneim, and Hisham., "Determining the Opimum HF Concentration for Stimulating of High Temperature Sandstone Formation", SPE European Formation Damage Conference and Exhibition held Budapest, Hungaray, 2015. 


\section{Appendix}

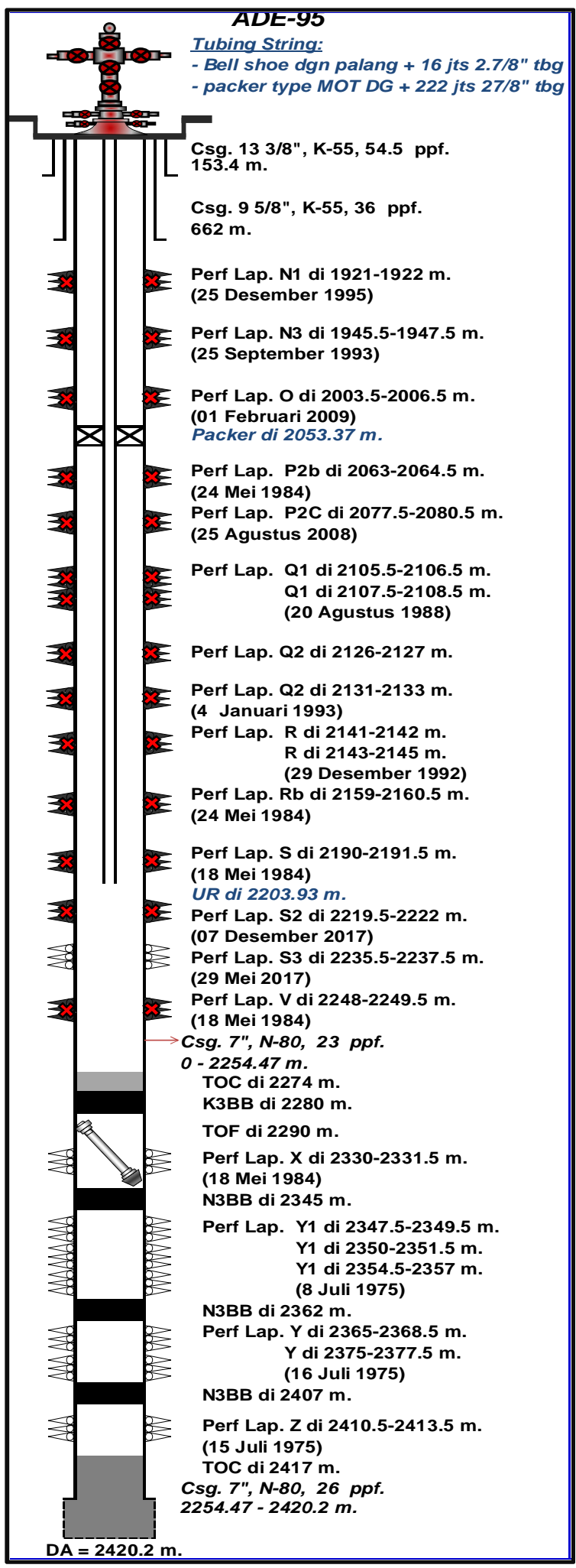

Figure 1: Well Perforation Interval "X" 


\begin{tabular}{|c|c|}
\hline Formasi & Main Acid \\
\hline \multirow{3}{*}{$\begin{array}{l}\text { Kelarutan dalam } \mathrm{HCl}>15-20 \% \\
\text { Calcite atau dolomite } \\
\text { High Iron Carbonate (ankerire, siderite) }\end{array}$} & \\
\hline & $15 \% \mathrm{HCl}$ \\
\hline & $15 \% \mathrm{HCl}+$ iron control \\
\hline \multicolumn{2}{|l|}{ Permeabilitas Tinggi ( $>100 \mathrm{mD}$ ) } \\
\hline \multirow{6}{*}{$\begin{array}{l}\text { High quartz }(>80 \%) ; \text { low clay }(<5 \%) \\
\text { Moderat clay }(<5-8 \%) \\
\text { High clay }(>10 \%) \\
\text { High feldspar }(>15 \%) \\
\text { High feldspar }(>15 \%) \text { dan high clay }(>19 \%) \\
\text { High iron chlorile clay }(>-8 \%)\end{array}$} & $12 \% \mathrm{HCl}-3 \% \mathrm{HF}$ \\
\hline & $7,5 \% \mathrm{HCl}-1,5 \% \mathrm{HF}$ \\
\hline & $6,5 \% \mathrm{HCl}-1 \% \mathrm{HF}$ \\
\hline & $13,5 \% \mathrm{HCl}-1,5 \% \mathrm{HF}$ \\
\hline & $9 \% \mathrm{HCl}-1 \% \mathrm{HF}$ \\
\hline & $\begin{array}{l}3 \% \mathrm{HCl}-0,5 \% \mathrm{HF} \text { atau } \\
10 \% \text { acetic }-0,5 \% \mathrm{HF}\end{array}$ \\
\hline \multicolumn{2}{|l|}{ Permeabilitas Menengah (10-100 mD) } \\
\hline \multirow{6}{*}{$\begin{array}{l}\text { Higher clay }(>5-7 \%) \\
\text { Lower clay }(<5-7 \%) \\
\text { High feldspar }(>10-15 \%) \\
\text { High feldspar }(10-15 \%) \text { dan high clay }\end{array}$} & $6 \% \mathrm{HCl}=1,5 \% \mathrm{HF}$ \\
\hline & $9 \% \mathrm{HCl}-1 \% \mathrm{HF}$ \\
\hline & $12 \% \mathrm{HCl}-1,5 \% \mathrm{HF}$ \\
\hline & $9 \% \mathrm{HCl}-1 \% \mathrm{HF}$ \\
\hline & $3 \% \mathrm{HCl}-0,5 \% \mathrm{HF}$ \\
\hline & $10 \%$ acetic $-0,5 \% \mathrm{HF}$ \\
\hline \multirow[t]{2}{*}{ High iron carbonate (>5-7\%) } & $9 \% \mathrm{HCl}-1 \% \mathrm{HF}$ \\
\hline & $5 \% \mathrm{HCl}-0,5 \% \mathrm{HF}(\mathrm{k}<25 \mathrm{mD})$ \\
\hline \multirow{5}{*}{$\begin{array}{l}\text { Perm eabilitas Rendah }(1-10 \mathrm{mD}) \\
\text { Low Clay }(<5 \%) ; \text { Kelarutan dalam } \mathrm{HCl}(<10 \%) \\
\text { High clay }(>8-10 \%) \\
\text { High iron chlorite clay }(>5 \%) \\
\text { High feldspar }(>10 \%)\end{array}$} & \\
\hline & $6 \% \mathrm{HCl}-1,5 \% \mathrm{HF}$ \\
\hline & $3 \% \mathrm{HCl}-0,5 \% \mathrm{HF}$ \\
\hline & $10 \%$ acetic- $0,5 \% \mathrm{HF}$ \\
\hline & $9 \% \mathrm{HCl}-1 \% \mathrm{HF}$ \\
\hline
\end{tabular}

Table 1: Selection Based Acid Formation Source: HO Mcleod, 1989

\begin{tabular}{|c|c|}
\hline PWF, psig & Q, bfpd \\
\hline 0 & 352 \\
\hline 300 & 326 \\
\hline 600 & 297 \\
\hline 900 & 264 \\
\hline 1200 & 228 \\
\hline 1500 & 189 \\
\hline 1800 & 146 \\
\hline 2100 & 101 \\
\hline 2200 & 69 \\
\hline 2300 & 36 \\
\hline 2531 & 31 \\
\hline 2708 & 0 \\
\hline
\end{tabular}

Table 2: Data PWF And Q Before Matrix Acidizing

\begin{tabular}{|c|c|}
\hline PWF, psi & Q, bfpd \\
\hline 0 & 1143 \\
\hline 300 & 1057 \\
\hline 600 & 959 \\
\hline 900 & 851 \\
\hline 1200 & 732 \\
\hline 1500 & 605 \\
\hline 1800 & 468 \\
\hline 2100 & 322 \\
\hline 2300 & 220 \\
\hline 2500 & 114 \\
\hline 2531 & 98 \\
\hline 2708 & 0 \\
\hline
\end{tabular}

Table 3: After PWF and Q Data Matrix Acidizing 




Figure 2: Comparison of IPR Before and After Matrix Acidizing



Figure 3: Well Logswells X 